\title{
BOEZEM WONOREJO RUNGKUT DI GUNUNG ANYAR SEBAGAI ALTERNATIF PENGENDALI BANJIR DI WILAYAH SURABAYA SELATAN
}

\author{
Oleh : Kusnan *)
}

\begin{abstract}
Abstrac
Surabaya as the Capital of East Java Province is a settlement area and also as the centers of Industry, Trade, Service, Education. Due to the development of all activities lines grow rapidly, including the supplying of housing, industrial plants, thus automatically they change the land functions (land use), and the river functions formerly as the irrigation but now changed to be the drainage, causing the increasingly large of flow coefficient, also increasingly large the surface overflow discharge. With the changes, they change irrigation canal functions become the drainage, that bring the river constriction impact, that the river no longer able to hold and channeling flood discharge both come from the upper course, and due to the local rainfall occurred continually in the dry season, water will overflow to flood the areas with the low elevation under sea level, causing the prolonged water backup, as a result, disturb the economy wheel circulation, causing the big losses. To overcome backup water many things we can perform, such as waterworks widening, sediment dredging, and the making of dike heightening, waterway diversion. By the consideration that costing is expensive and the difficult of area (land) deliverance at the settlement area in order to overcome the water backup/flood, then the solution as alternative can be taken is revitalization of Wonorejo Boezem in Gunung Anyar of Rungkut area, where its land is not productive (non productive fishpond area) with the shallow condition. Instead of revitalization, it is also developed the new construction or enlargement of reservoir capacity in the Boezem. From the results of this research consistent with the work items result in as follows: Sum the design flow discharge as much as $51.4863 \mathrm{~m}^{3} / \mathrm{s}\left(\right.$ C.I.A) $+0,446$ (gross water discharge people) $+0.3327 \mathrm{~m}^{3} \mathrm{~s}$ (gross water discharge Industry) $=52.165 \mathrm{~m}^{3} / \mathrm{s}$ with the repeated period scale of 10 years, while the reservoir discharge capacity of Wonorejo Boezem as much as less than 570,874 $\mathrm{m}^{3}$ need th design flow discharge as much as $586.000 \mathrm{~m}^{3} \mathrm{~s}$ and the drainage flowing water to the Boezem, the drainage dike height is $1.50 \mathrm{~m}$ with water level of 1.25 meters and wide 28 meters, then in order to suppress the budget costing for flood control in Southern Surabaya Area, as the alternative is by function maximally on the Wonorejo Boezem reservoir, still sufficiently can overcome flood.
\end{abstract}

Key words: Wonorejo Boezem to overcome Flood.

\section{PENDAHULUAN}

Surabaya adalah merupakan kota Industri dan perdagangan yang sangat penting di Idonesia. Sebagai ibu kota propinsi Jawa Timur dan kota terbesar setelah Jakarta, kota ini mempunyai jumlah penduduk kurang lebih $3,5 \mathrm{~s} / \mathrm{d} 4$ juta pada tahun 2009 dan luas daerahnya \pm 290 ha. Bila dlihat dari letak secara geografi lokasi kajian sangat dekat dengan tepi laut (pantai Kenjeran) dan ketinggian dari permukaan air laut $+0 \mathrm{~s} / \mathrm{d} 5 \mathrm{~m}$ atau hampir sejajar dengan permukaan air laut. Oleh karena itu dengan ketinggian yang rendah ini, bila pada saat musim penghujan sering menimbulkan banjir atau genangan air yang cukup lama tidak mengering dan cukup meresahkan masyarakat serta mengganggu sirkulasi perekonomian perkotaan.

Perlu diketahui bahwa pembuangan air kotor, maupun dari hujan dibagian tepi lautan sangat sulit, dimana hal ini disebabkan oleh elevasi permukaan air laut sama tingginya dengan elevasi daratan. Sehingga mengakibatkan kondisi terburuk atau banjir pada saat laut pasang bersamaan dengan datangnya hujan yang cukup lebat. dan pada saat ini akan terjadi back water, yaitu merambatnya gelombang pasang menuju ke hulu (muara), sehingga air tidak dapat mengalir ke muara. Untuk mengatasi hal ini dapat dilakukan beberapa cara- cara seperti normalisasi sungai, peninggian tanggul, sudetan, pembuatan sumur resapan, dan penanaman penghijauan pohon (pohon yang bersifat menyerap air).

\footnotetext{
*) Dosen Fakultas Teknik Sipil Universitas Negeri Surabaya
} 
Adapun pemilihan alternatif tersebut didasarkan pada kondisi daerah studi yang paling memungkinkan baik dari segi kekuatan struktur kondisi lahan itu sendiri, maupun dari segi ekonomis. dengan pertimbangan kondisi alam yang ada, maka solusi yang paling sesuai adalah dengan merevitalisasi Boezem yang ada, pebaikan/perluasan menambah daya tampungan, salah satunya adalah Boezem Wonorejo di desa Gunung Anyar yang terletak di lokasi Surabaya Timur.

Adapun Boezem Wonorejo telah dibangun dalam 3 (tiga) tahapan yaitu : tahap I dibangun pada tahun 2001 seluas 2,5 ha, tahap ke II seluas 2,5 ha tahun 2002 dan tahap III (ketiga) seluas 3 ha pada tahun 2003. Namun setelah pembangunan Boezem tersebut selesai tuntas dilaksanakan, ternyata pada musim hujan tiba masih selalu terdapat genangan atau banjir yang cukup lama genangan air tidak cepat mengering. Dengan demikian, fungsi Boezem Wonorejo Desa Gunung Anyar tersebut masih belum optimal fungsinya dalam menanggulangi banjir di Kota Surabaya, terutama pada daerah Kecamatan Wonocolo dan Wonosari (Surabaya Selatan dan Timur), yang berarti untuk Boezem Wonorejo termasuk saluran drainasenya perlu evaluasi kembali, untuk diadakan revitalisi/rehabilitasi Dari perkembangan pertambahan penduduk dari tahun ke-tahun, telah diikuti pula oleh berkembangnya tambahan pembangunan penyediaan papan (perumahan) dan fasum, sehingga penyelesaian mengenai penanggulangan masalah banjir harus perlu diantisifasi bersamaan mengikuti masalah tersebut diatas.

Permasalahan yang terdapat di lapangan yang akan direncanakan redisign adalah drainasenya yaitu dengan menggunakan alternatip memperbesar/memperdalam dimensi saluran pembuangan air hujan ke Boezem yang ada di daerah Rungkut, wilayah Surabaya Timur. Dalam studi ini penelitian adalah redisign besaran tampungan debit rencana yang terjadi memakai kala ulang 5 tahun, dengan air buangan sesuai proyeksi perkembangan penduduk tahun 2010 , industri, total air buangan dan redesign dimensi saluran (drainage) , termasuk perbaikan atau rehabilitasi Boezem yang ada sekarang.

\section{KAJIAN KEPUSTAKAAN \\ 1. Analisa Hidrologi \\ a. Hujan Rerata Daerah}

Curah hujan yang diperlukan untuk penyusunan suatu Debit rancangan dan pemanfaatan air, yang dipakai sebagai pengendalian banjir, serta sebagai penentu dimensi drainase (saluran) adalah diambil dari data curah hujan rata-rata diseluruh daerah yang bersangkutan (Kebon-agung, Wonorejo, Wonokromo), dan Curah hujan ini dinyatakan dalam ukuran milimeter (Sosrodarsono, 1983), untuk mendapatkan data tersebut dapat mengunakan 3 (tiga) cara antara lain :

a. Cara rerata aljabar/hitung

b. Cara poligon thiessen

c. Cara Isohyet

Harga rata-rata hitung didapatkan dengan menjumlahkan curah hujan dari semua tempat pengukuran selama suatu periode tertentu (1- 5 hari maksimum), dengan kala ulang 5 tahun, dan membaginya dengan banyaknya tempat pengukuran.

Dalam penelitian digunakan dengan cara Poligon Thiessen, karena dianggap bahwa data curah hujan dari suatu tempat pengamatan dapat dipakai untuk daerah pengaliran disekitar tempat itu, yaitu pada stasiun Kebon Agung, Wonokromo dan Wonorejo (hasil pencatatan diolah/analisi dengan cara Polygon Thiessen.

\section{b. Analisa lengkung Massa Ganda}

Analisa Lengkung Massa Lengkung Ganda adalah pengujian ketangguhan atau konsistensi data suatu stasiun setelah dilakukan perbaikan/pengisian data curah hujan beserta akumulasinya dan dibandingkan dengan stasiun hujan yang terdekat lainnya (di DAS lokasi penelitian).

\section{c. Curah Hujan Rancangan}

Untuk mendapakan hitungan Debit hujan rancangan maksimum, memakai kala ulang 5 (lima) tahun, menggunakan perumusan curah hujan rancangan dengan log Person Type III sebagai kelengkapan untuk perhitungan dimensi Saluran (Drainase). Adapun Langkahlangkah urutan perhitungan sebagai berikut :

$>$ Data curah hujan $x 1, x 2, x 3 \ldots . . x n$ menjadi $\log x 1 \ldots . . \log x n$

$>$ Rerata log 


$$
\begin{gathered}
\bar{x}=\sum_{i=1}^{n} \frac{\log X_{1}}{n} \\
\text { Simpangan baku } 3 n=\sqrt{\frac{\left(\log X_{n}-\log X\right)^{2}}{n-1}} \\
>\text { Skewness Cs } \\
\quad s=\frac{n\left(\log X_{n}-\log X\right)^{3}}{(n-1)(n-2) S n^{3}} \\
>\text { Menghitung logaritmatik hujan } \\
\text { dengan kala ulang yang diinginkan } \\
\text { Log } X=\log X+\text { K. Sn }
\end{gathered}
$$

\section{d. Uji Kecocokan}

Untuk menentukan uji kecocokan (the goodness of fit test) distribusi frekuensi dari sampel data terhadap fungsi distribusi peluang yang diperkirakan dapat menggambarkan / mewakili distribusi frekuensi tersebut diperlukan pengujian parameter melalui uji:

1. Chi-Kuadrat (chi-square)

2. Smirnov-Kolmogorov

\section{e. Koefisien Pengaliran}

Koefisien pengaliran diperoleh dari hasil perbandingan anatara jumlah air yang mengalir sebagai limpasan dari suatu hujan di permukaan tanah tertentu dengan jumlah total air hujan yang jatuh. Pada perencanaan bangunan-bangunan air, nilai koefisien pengaliran (C) harus diupayakan sekecil mungkin yakni air hujan yang menjadi limpasan kecil, sedangan yang terinfiltrasi sebanyak mungkin agar dimensi bangunanbangunan air tersebut sekecil mungkin dan untuk menentukan factor-faktor yang mempengaruhi koefisien pengaliran ini diambilkan pada umumnya sudah standart ( Ditjen Pengairan Indonesia).

\section{f. Waktu Konsentrasi, Analisa Intensitas} Hujan dan Hidrograf

1. Waktu Kosentrasi adalah waktu yang diperlukan untuk mengalirnya air hujan dari titik terjauh menuju suatu titik tertentu yang ditinjau pada daerah pengaliran. Waktu di saluran (td) adalah waktu yang diperlukan air hujan untuk mengalirkan dari saluran ke suatu titik tertentu yang ditijau. Sedangkan waktu Overland Flow (to) adalah waktu yang diperlukan untuk air hujan dari titik jatuh air pada permukaan tanah menuju saluran terdekat. Dalam hubungan waktu ini dapat dirumuskan sebagai berikut :

tc $=$ to + td dimana $t d=L / V$

2. Analisa Intensitas Hujan adalah untuk memperoleh data curah hujan dalam suatu tertentu jangka pendek (dalam lama waktu menit, detik) yang dapat dicatat pada alat penakar atau pencatat curah hujan diubah menjadi intensitas curah hujan per jam. Agar dalam menentukan besaran limpasan air permukaan pada priode per-jam dapat diketahui.

Ada beberapa perumusan dalam menghitung intenitas hujan diantaranya : Talbot, Sherman, Ishiguro, dan Monotobe, sedangkan untuk keperluan ini dipilih perumusan:

$I=R 24 / 24(24 / t c)^{m}$

3. Hidrograf adalah suatu grafik yang menggambarkan hubungan antara tinggi permukaan air atau debit terhadap waktu. Untuk membuat hidrograf banjir pada sungai-sungai yang tidak ada atau sedikit sekali dilakukan observasi hidrograf banjirnya, maka perlu dicari karakteristik atau parameter daerah pengaliran tersebut terlebih dahulu, hal ini untuk mencari / mengetahui waktu untuk mencapai puncak hidrograf, lebar dasar, luas kemiringan, panjang alur terpanjang, koefisien limpasan, dan sebagainya. Dalam pemakai hidrograf-hidrograf sudah banyak di Negara lain telah dikembangkan, yaitu dengan cara penyesuaian terlebih dahulu parameter-parameter terakait yang disesuaikan pada sifat karakteristik masing-masing daerahnya (DAS).

Ada beberapa Hidrograf Satuan Sintetik yang dikembangkan yaitu Hidrograf Satuan Sintetik Snyder dan Hidrograf Nakayasu. Dalam studi penelitian ini untuk perencanaan biasanya digunakan Hidrograf Satuan Sintetik Nakayasu dengan perumusan :

$$
Q p=C \cdot A \cdot R o / 3,6(0,3 \mathrm{Tp}+\text { To,3) }
$$

\section{Debit Buangan air kotor penduduk dan} Industri / pabrik.

a. Untuk merencanakan suatu dimensi Boezem diperlukan perhitungan Debit buangan air kotor yang diakibatkan oleh jumlah penduduk selama proyeksi kedepan selama 5 tahun, 

Surabaya Selatan

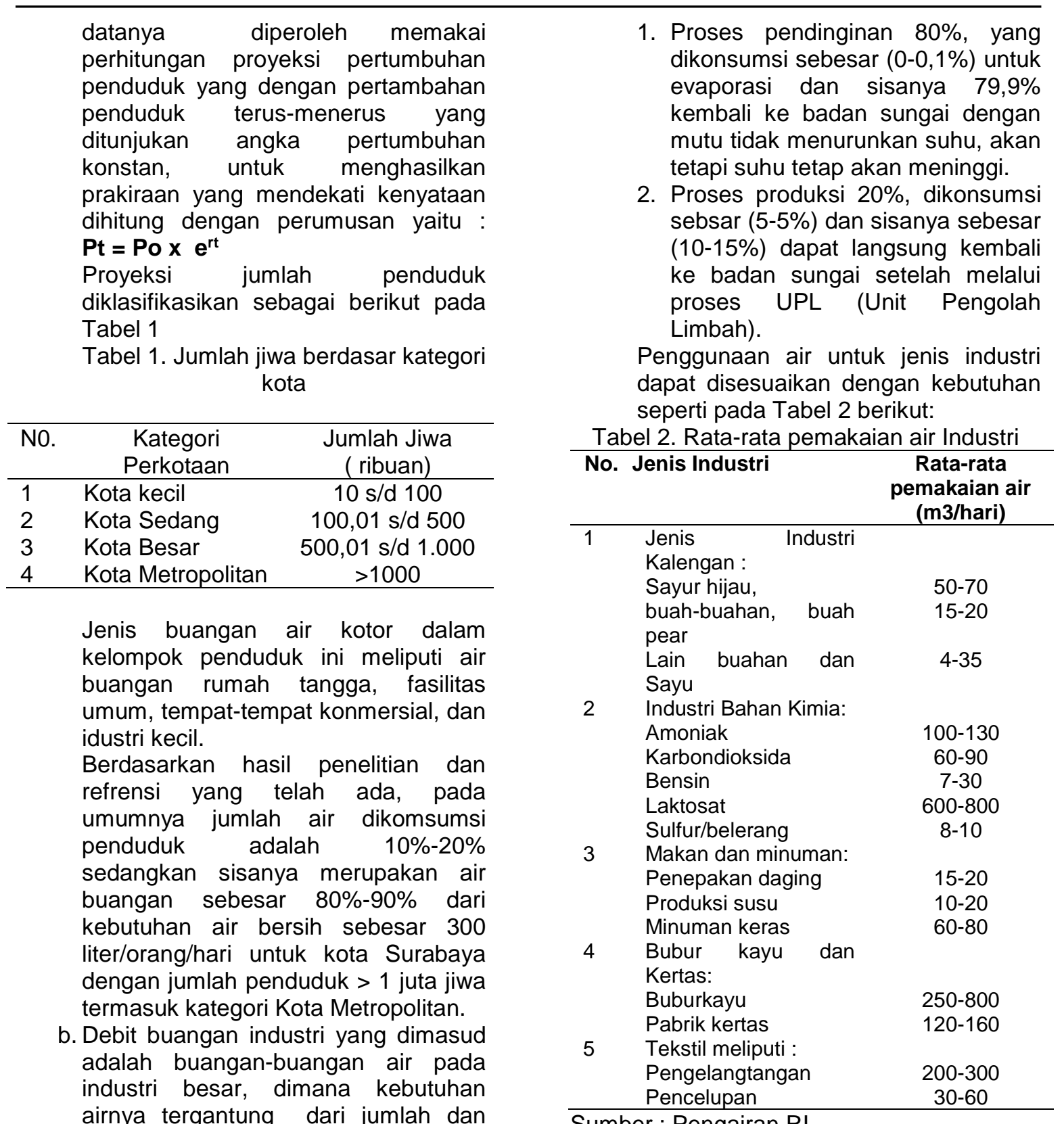
jenis industri tersebut. Berdasarkan refrensi dan hasil penelitian yang ada sebelumnya, air yang digunakan berasal dari air tanah dan sungai, kebutuhan air seperti uraian berikutnya:

\section{Perencanaan Dimensi Saluran (inlet).}

Dalam penelitian ini akan direncanakan saluran berbentuk trapesium dengan kemiringan $z=1,0$ seperti Gambar 1 Adapun perumusan yang digunakan adalah : 


\section{w}

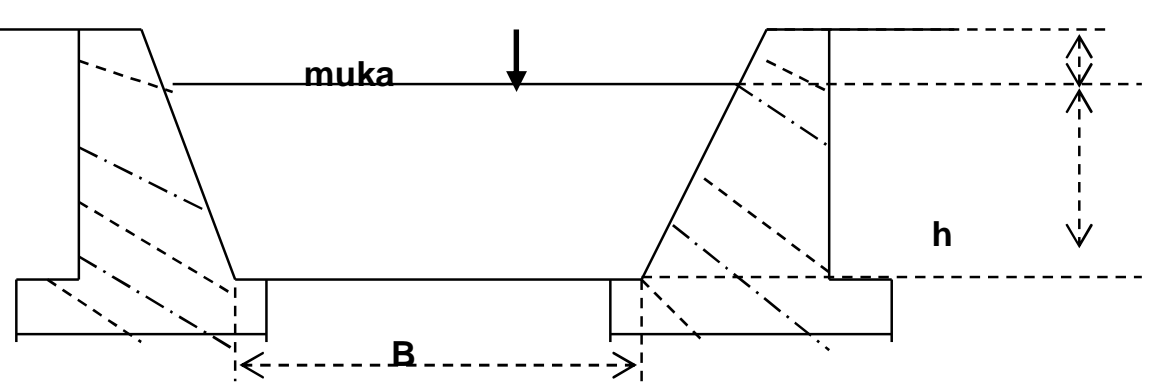

air

Gambar 1 Konstruksi Saluran ke Boezem Perumusan Perencanaan :

$$
\begin{gathered}
A=B \cdot h+z \cdot h \\
P=B+2 \cdot h \cdot \sqrt{1+Z^{2}} \\
R=A / P \\
V=1 / n . R^{2 / 3} \cdot S^{1 / 2 .}
\end{gathered}
$$

Adapun nilai $\mathrm{n}$ tergantung pada jenis saluran yang digunakan, seperti pada Tabel 3.

Tabel 3 Kemiringan saluran (n)

\begin{tabular}{clc}
\hline No. & \multicolumn{1}{c}{ Permukaan } & $\begin{array}{c}\text { Harga } \mathbf{~} \\
\text { yang } \\
\text { disarankan }\end{array}$ \\
\hline 1 & Kaca,Plastik, kuningan & 0,010 \\
2 & Plesteran semen & 0,011 \\
3 & Besi Tulang & 0,013 \\
4 & Beton & $0,012-0,017$ \\
5 & Pipa pembuang & 0,013 \\
6 & Batu Bata & 0,014 \\
7 & Pasangan Batu & $0,017-0,025$ \\
8 & Kayu & $0,011-0,014$ \\
9 & Batu Pecah & $0,035-0,040$ \\
\hline \multicolumn{2}{l}{ Sumber : KG. Rangga Raju, 1986. }
\end{tabular}

\section{HASIL DAN PEMBAHASAN}

1. Curah Hujan.

Hasil data curah hujan yang jatuh di daerah kajian atau daerah aliran Sungai (DAS) Wonokromo luas $=1,095 \mathrm{~km} 2$, Kebon agung $=2,66 \mathrm{~km} 2$ dan Wonrejo $=12,274$ $\mathrm{km} 2$, jika dalam pengeloaan digunakan metode Polygon Thiessen, maka masingmasing Stasiun mempunyai koefisien Thiessen yang lebih dahulu dapat dicari, dengan cara luas area masing-masing Stasiun dibagi Jumlah total luas area Stasiun, sehingga mendapatkan Koefisen Thiessen pada Stasiun : Wonokromo, Kebon agung, Wonorejo, kemudian hasil koefisien dikalikan data masing-masing daerah yang bersangkutan, perhitungan data ini mulai tahun 1985 sampai dengan 2004, mendapatkan hasil seperti pada Tabel 4 .

Tabel 4 Hasil perhitungan curah hujan maximum yang terjadi di Stasiun Wonokromo,Kebonagung,Wonorejo

\begin{tabular}{cccccccc}
\hline $\begin{array}{c}\text { Priode } \\
\text { Tahun }\end{array}$ & $\begin{array}{c}\text { Curah } \\
\text { hujan max }\end{array}$ & Tahun & $\begin{array}{c}\text { Curah } \\
\text { hujan max }\end{array}$ & Tahun & $\begin{array}{c}\text { Curah } \\
\text { hujan max }\end{array}$ & Tahun & $\begin{array}{c}\text { Curah } \\
\text { hujan max }\end{array}$ \\
\hline 1985 & 81,78 & 1990 & 68,16 & 1995 & 79,76 & 2000 & 62,18 \\
1986 & 96,02 & 1991 & 65,35 & 1996 & 79,77 & 2001 & 100,04 \\
1987 & 93,75 & 1992 & 92,31 & 1997 & 108,30 & 2002 & 118,39 \\
1988 & 79,24 & 1993 & 68,23 & 1998 & 23,16 & 2003 & 79,31 \\
1989 & 72,12 & 1994 & 61,285 & 1999 & 96,25 & 2005 & 51,00 \\
\hline
\end{tabular}

Dari data tersebut pada Tabel 4 diurutkan dari besaran kecil, kemudian dianalisis memakai cara perumusan Log Person III, dengan kala 5 tahun menghasilkan Debit hujan rancangan $Q=$ $118,41 \mathrm{~mm}$

\section{Analisa lengkung Massa Ganda}

Pengujian kevalid (kebenaran) data dilakukan dengan Analisa Lengkung Massa Ganda dengan menghitung curah hujan tahunan berserta akumulasinya dan dibandingkan dengan Stasiun hujan terdekat, untuk menguji ketelitan kevalidan (kebenaran) data.

\section{a. Uji kecocokan Distribusi}

Uji kecocokan distribusi dengan metode Chi Square, dengan jumlah data $n=20$ dan jumlah kelas $(G)=1+$ 1,33 Ln.20, dalam pengamatan dibagi menjadi 5 (lima) sub bagian dengan interval peluang $p=1 / 5$ dengan grup 
$1=\mathrm{P} \leq 0,2$, grup $2=\mathrm{P} \leq 0,4$, grup $3=\mathrm{P} \leq$ 0,6 , grup $4=P \leq 0,8$ dan grup $5=P \leq$ 1,00 ., diambil peluang $5 \%$ artinya data dapat dierima bila $\mathrm{dk}=2$ dengan persamaan lengkung kerapan $\log X$ mendapatkan $\mathrm{Cs}=0,6364$ hasil dari uraian tersebut dapat dilihat Tabel 5 .

Tabel 5 Hasil Perhitungan Log Person III

\begin{tabular}{ccccccc}
\hline $\mathbf{P}$ & $\mathbf{T}$ & $\mathbf{C s}$ & Lox X & Sn Log X & $\mathbf{K}$ & $\log \mathbf{X}$ \\
\hline 0,2 & 5 & $-0,636$ & 1,8572 & 0,4335 & 0,857 & 1,997 \\
0,4 & 2,5 & $-0,636$ & 1,8572 & 0,4335 & 0,23 & 1,975 \\
0,6 & 1,67 & $-0,636$ & 1,8572 & 0,4335 & 0,022 & 1,885 \\
0,8 & 1,25 & $-0,636$ & 1,8572 & 0,4335 & $-0,082$ & 1,830 \\
\hline
\end{tabular}

Tabel 6. Perhitungan Uji Kecocokan Chi Square Distribusi og Person III

\begin{tabular}{|c|c|c|c|c|c|}
\hline \multirow{2}{*}{ No. } & Nilai Batas & \multicolumn{2}{|c|}{ Jumlah Data } & \multirow{2}{*}{$(0 \mathrm{i}-\mathrm{Ei})^{2}$} & \multirow{2}{*}{$(0 \mathrm{i}-\mathrm{Ei}) / \mathrm{Ei}$} \\
\hline & Sub Kelompok & $\mathbf{0 i}$ & $\mathrm{Ei}$ & & \\
\hline 1 & $R<1,830$ & 5 & 4 & 1 & 0,250 \\
\hline 2 & $1,830<R<1,885$ & 3 & 4 & 1 & 0,250 \\
\hline 3 & $1,885<R<1,975$ & 7 & 4 & 9 & 0,250 \\
\hline 4 & $1,975<R<1,997$ & 2 & 4 & 4 & 1,000 \\
\hline 5 & $R>1,997$ & 3 & 4 & 1 & 0,250 \\
\hline & Jumlah & 20 & 20 & - & 4 \\
\hline
\end{tabular}

Dari hasil perhitungan $\mathrm{dk} 2$ dan $\mathrm{P}=$ $5 \%$ dan Nilai Kritis untuk distribusi ChiKadrat (uji satu sisi) Evaluasi nilai $\mathrm{X} \mathrm{kr}=$ 5,991 > S (0i-Ei) ${ }^{2} /$ Ei 5,991> 4,000 (ok).]

Bedasarkan perhitungan persamaan distribusi peluang yang telah terpilih (Distribusi Log Person III) data dapat mewakili distribusi statistik sampel data yang dianalisis.

\section{Perhitungan koefisien Pengaliran.}

Berdasarkan tataguna lahan Kota Surabaya tahun 2005, diperoleh data untuk DAS Kali Surabaya - Saluran untuk daerah wilayah Wonorejo sebagai berikut: Perumahan pemukiman $(\mathrm{C} 1=0,70)$ dengan luas area $8,7 \mathrm{~km}^{2}$, Fasilitas Umum $(\mathrm{C} 2=0,90)$ dengan luas area $2,45 \mathrm{~km}^{2}$, Industri $\quad(\mathrm{C} 3=0,90)$ dengan luas area $1,00 \mathrm{~km}^{2}$ dan Ruang terbuka hijau $(C 4=0,20)$ luas area 0,10 $\mathrm{km}^{2}$, jika dihitung secara rata-rata mendapatkan hasil perhitungan koefisien pengaliran $\mathbf{C}=\mathbf{0 , 7 5 2 2}$,

\section{Perhitungan Waktu Kosentrasi}

Waktu kosentrasi yang dibutuhkan adalah dengan rumusan
a. $\mathrm{Sr}=\quad \sum . \mathbf{L i} \cdot \mathrm{Si}^{\mathbf{0}, 5} \quad / \sum . \mathbf{L i} \quad 2=$
$(14,7 \cdot 0,03 \cdot 05 / 14,7)^{2}=0,03 \%$
dimana :
$\mathrm{Si}=\Delta \mathrm{h} / \mathrm{L}=0,03$
$\Delta \mathrm{h}=$ beda tinggi hulu dan hilir $=4 \mathrm{~m}$
$\mathrm{L}=14,7 \mathrm{~m}$ ( panjang saluran)

b. Waktu tc ( waktu puncak)

$$
\begin{aligned}
\text { tc }= & 92,7 \mathrm{~L} /(\mathrm{A})^{0,1}(\mathrm{Sr})^{0,2}=92,7 \mathrm{x} \quad 14,7 \\
& /(12,25)^{0,1}(0,03)^{0,2}=2139 \text { detik }= \\
& 35,65 \text { menit } \\
\text { tc }= & 0,594 \text { jam. }
\end{aligned}
$$

\section{Analisa Intensitas Hujan.}

Besaran Intensitas curah hujan rancangan 24 jam dari hasil perhitungan Log Person III dengan kala ulang 5 tahun, $\mathrm{R} 24=118,41 \mathrm{~mm}$, dengan tc $=0,594$ jam $\mathrm{I}=\mathrm{R} 24 / 24(24 / \mathrm{tc})^{\mathrm{m}}=118,41 / 24$

$(24 / 0,594)^{2 / 3}=58,09=58,1 \mathrm{~mm} / \mathrm{jam}$

\section{Perhitungan Hidrograf Banjir} Rancangan

Perhitungan hidrograf Satuan Sintentik Nakayasu

a. Waktu Konsentrasi, $\operatorname{tg}=0,21 \cdot \mathrm{L}^{0,7}=$ $0,21(1,47)^{0,7}=1,378$ jam

b. Lama Hujan, $\operatorname{tr}=(0,5+1) \operatorname{tg}=(05,+1)$ $, 378=2,067$ diambil 1 jam

c. Tegang waktu dari awal sampai puncak

$\mathrm{Tp}=\mathrm{tg}+0,8 . \mathrm{tr}$

$=1,378+0,8 .(1)=2,2 \mathrm{jam}$,

untuk $\mathrm{TO}, 3=2 \quad \mathrm{tg}=2 \cdot 1,378=2,8 \mathrm{jam}$

d. Debit puncak akibat hujan $1 \mathrm{~mm}, \mathbf{Q p}$ $\mathrm{Qp}=$ C.A $. R o / 3,6\{0,3(\mathrm{Tp})+\mathrm{T} 0,3\}$ $=0,7522 \cdot 12,25 \cdot 1 / 3,6\{0,3(2,2)+2,8\}$ $=0,740 \mathrm{~m} 3 / \mathrm{dt}$,

kemudian perhitungan persamaan sisi naik hidrograf $Q a$ dan persamaan sisi resesi hidrograf $\mathbf{Q d}$, jika selama kejadian 6 jam $\mathrm{V}=158$ jam-m ${ }^{3}$ 
7. Perhitungan Debit Rancangan yang terjadi

a. Debit pembuangan Penduduk

Perhitungan debit buangan pemungkiman didasarkan pada air buangan penduduk yang berada dalam DAS Kali Surabaya-Intake Saluran Wonorejo pada saat ini dengan proyeksi pertumbuhan jumlah penduduk 5 (lima) tahun mendatang. Adapun perhitungan air buangan penduduk merupakan prosentase dari kebutuhan air dimasing-masing berdasarkan, jumlah penduduk adalah : Jumlah penduduk $\mathrm{Po}=$ 349.965 jiwa $\mathrm{Pt}=(39,965) \quad \mathrm{x}$ $2,71828^{(0,015.5)}=366.088$ jiwa

Jumlah penduduk kategori Kota sedang, maka proyeksi jumlah penduduk termasuk $1001.000 \mathrm{~s} / \mathrm{d}$ 500.000 jiwa, sedangkan kebutuhan air perkapita 150 It/hari/orang. Sehingga kebutuhan air pembuangan $=$ Kebutuhan air penduduk kebutuhan konsumsi yaitu $(366,088 \times 150)-15 \%(366,088 \times 150)$ $=0,446 \mathrm{~m} 3 / \mathrm{dt}$.

b. Debit Pembuangan Industri dan kebutuhan air.

Kebutuhan air untuk Industri sesuai Standart Nasional Indonesia (SNI) dalam asumsi 10 jam kerja (termasuk jam kerja lembur) adalah 0,135 m3/dt, perhitungan kebutuhan air buangan adalah Air buangan pabrik + Air buangan pendinginan yaitu : $((20 \% \mathrm{x}$ $0,135) \quad 8 \%$ $(20 \% \times 0,135)+(80 \% \times 0,35)-$ $0,1 \% \times(80 \% \quad \times \quad 0,135)$ $=0,0225 \mathrm{~m} 3 / \mathrm{dt}+0,1079 \mathrm{~m} 3 / \mathrm{dt}=0,333 \mathrm{~m} 3 /$ dt.

c. Debit rancangan (Debit total).

Debit total atau debit rancangan yang diperoleh selanjutnya akan digunakan dalam perencanaan dimensi saluran dan dimensi tampungan (Boezem). Debit total atau rancangan tersebut adalah $\mathrm{Q}=\mathrm{C} . \mathrm{I} . \mathrm{A}+0,446+0,3327$

$\mathrm{Q}=0,722 . \times 58,1 \times 12,25+0,7787$ $=52,165 \mathrm{~m} 3 / \mathrm{dt}$

\section{Perencanaan dimensi Saluran}

Dasar kemiringan saluran $S=0,003, Z=1$, Koefisien manning $n=0,017$, Debit total (sebagai debit rencana untuk data perhitungan) $=52,154 \mathrm{~m} 3 / \mathrm{dt}$ dan Kecepatan $V=1,2 \mathrm{~m} / \mathrm{dt}$ (sebagai asumsi awal).
Direncana $B=19 . h$ dengan pertimbangan mereduksi besaran $h$ sedemikian, agar elevasi dasar saluran bagian hilir tidak lebih dari muka air laut.

$\mathrm{Q}=\mathrm{V}$. A

$A=Q / V=52,154 / 1,2=43,462 \mathrm{~m}^{2}$

$\mathrm{A}+\mathrm{B} \cdot \mathrm{h}+\mathrm{z} \cdot \mathrm{h}^{2}$

$43,462=19 h \cdot h+1,0 \cdot h^{2}$

$43,462=20 . h^{2}$

$\mathrm{h}=1,474$ dibulatkan menjadi $1,50 \mathrm{~m}$

$B=19 \times 1,474=28 \mathrm{~m}$

\section{Perencanaan Boezem}

Besaran Boezem Wonorejo mempunyai kapasitas rencana kurang lebih $7,5 \times 8$ ha $=586.000 \mathrm{~m} 3$ dan posisi Debit banjir yang melewati mercu penyadap pintu keluar ditutup pada saat air laut pasang, pasang surut air laut ini terjadi dua kali setiap hari, yaitu selama waktu 6 jam, setelah itu pintu outlet dibuka kembali untuk mengalirkan air pasang yang ada di Boezem untuk di alirkan ke laut.

Dengan demikian, Kapasitas Boezem harus mampu menampung debit banjir yang terdiri dari limpasan hujan rancangan, debit buangan industri, dan Debit DAS diatasnya selama 6 jam. Kapasitas debit yang terjadi tersebut adalah :

a. Debit curah hujan dari hidrograf

Nakayasu selama 6 jam, $=\mathrm{V} 1$

$\mathrm{V} 1=158 \mathrm{jam}-\mathrm{m}^{3} / \mathrm{dt} \times 60 \times 60=568.000$ $\mathrm{m}^{3}$

b. Debit buangan penduduk selama 6 jam

$\mathrm{V} 2=0,466 \mathrm{~m}^{3} / \mathrm{dt} \times 60 \times 60=1.677 \mathrm{~m}^{3} / \mathrm{dt}$

c. Debit buangan Industri selam 6 jam

V3 $=0,333 \mathrm{~m}^{3} / \mathrm{dt} \times 60 \times 60=1197,7 \mathrm{~m}^{3} / \mathrm{dt}$

Total air buangan yang harus di tampung pada Boezem dengan $\mathrm{h}=7,50$ meter adalah $568.000+1677+1197,72=$ $570.874,72 \mathrm{~m}^{3}$ berarti sesuai penyediaan lahan untuk penampungan air limpasan, maupun buangan telah terpenuhi, untuk perbaikan dan perluasan, ini dibuktikan dengan Tampungan Boezem Wonorejo > besaran tampungan hasil penelitian.

\section{SIMPULAN}

a. Debit rancangan yang terjadi adalah $\mathrm{Q}$ rancangan total $=52,165 \mathrm{~m}^{3} /$ detik, adalah penjumlahan yang terdiri dari kejadian $Q$ debit rancangan akibat curah hujan hasil rumusan Rasional, Perhitungan air pembuangan dari perkembangan proyeksi jumlah kependudukan selama 5 tahun, 
perhitungan air buangan dari Industri/ Prabrik

b. Besar ukuran saluran inlet adalah $\mathrm{h}$ (kedalaman $)=1,50 \mathrm{~m}$ dan $\mathrm{B} \quad$ (lebar penampang basah) $28 \mathrm{~m}$, hal ini kalau dibanding ukuran kenyataan di lapangan bahwa kedalaman menunjukan lebih dalam 1,00 m, sehingga saluran Drainase Inlet telah memenuhi syarat, akan tetapi saluran yang ada dilapangan perlu adanya pengerukan sedimentasi.

c. Besaran ukuran Kapasitas tampungan Boezem dari hasil penyediaan lahan yang telah disiapkan oleh pemerintah Kota Surabaya sebesar 8 ha, daya tampungan $=586.000 \mathrm{~m}^{3}$, maka kapasitasnya tampungan telah memenuhi syarat dari hasil penelitian, hal ini ditunjukan pada besaran kapasitas yaitu: kapasitas tampungan $586.000 \mathrm{~m}^{3}>570.874,72 \mathrm{~m}^{3}$ dari kapasitas hasil penelitian, akan tetapi untuk SF (Safety Fctor masih perlu perluasan sebesar kisaran $750.000 \mathrm{~m}^{3}$.

d. Untuk pengoperasian teknis pintu Outlet perlu adanya penjaga yang selalu siap di Lapangan ( Boezem Wonorejo), karena dalam operasi penutupan maupun pembukaan harus dilakukan 2 (dua) kali sehari dalam tempo 6 jam, hal ini mengikuti pasang surutnya air laut pasang.

\section{DAFTAR PUSTAKA}

Anggraihini, 1997. Hidrolika Saluran Terbuka. Surabaya CV.Citra Media.

Anonim, 2003. Pengairan Dalam Angka 2003 DPU Propinsi Jawa Timur

Anonim , UU No 7 Tahun 2004 tentang Sumber Daya Air

Anonim ,UU No 22 Tahun 1999 tentang Otonomi Daerah

Chow.Ven Te 1989, Hidrolika Saluran Terbuka, Jakarta Penerbit Erlangga

Shahin, M,M,A, 1987, Statical Analysis Hidrologi Vol.2 Edition Depl Nederland

Soemarto, CD,1987, Hidrologi Teknik, Surabaya Usaha Nasional

Soebarkah, Imam.1980. Hidrolika Untuk Perencanaan Bangunan Air.Bandung Idea Dharma

Suhardjo.1984. Drainase Perkotaan Fakultas Teknik Universitas Brawijaya, Malang

Soewarno, 1991. Hidrologi. Bandung CV.Nova.

1995. Hidrologi Aolikasi Metode Statstik untuk Analisa data. Jilid I Bandung Nova

Sosdarsono,S..1980. Hidrologi Untuk Pengairan Jakarta : Pradya Paramita

www.google.2009.Drainase Permasalah .com

www.google.2009.Drainase Perkotaan. com

www.google.2009.Drainase persawahan .com

www.google.Penanganan Banjir .com

www.google Manfaat Drainase .com 